\title{
Strategies of Implementing a Green Building Assessment System in Mainland China
}

\author{
Qian Shi \\ Department of Construction Management and Real Estate \\ School of Economics and Management \\ Tongji University \\ China \\ E-mail: qianshi@mail.tongji.edu.cn
}

\begin{abstract}
The application of green building assessment tools have been widely accepted as an useful way to promote sustainable construction. This paper has analyzed present status of green building assessment in Mainland China and pointed out the strategies of developing an effective assessment system in a large developing country.
\end{abstract}

Keywords: Green Building Assessment, Sustainable Construction, Sustainable Development

\section{Introduction}

Since the early 1990s, sustainable construction has been widely accepted in the construction industry. Building houses to meet the present need, we must take care of not compromising the ability of future generations to meet their needs. According to World Watch, one-tenth of the global economy is dedicated to constructing, operating and equipping homes and offices. This activity accounts for roughly $40 \%$ of the materials flow entering the world economy, with much of the rest destined for roads, bridges and vehicles to connect the buildings. In 1999, the International Council for Research and Innovation in Building and Construction (CIB) published the Agenda 21 on Sustainable Construction (CIB,1999), which has clarified the main concepts, aspects and challenges that sustainable development presents to civil construction.

To realize sustainable development in the construction industry, building environmental assessment methods, which are designed to promote environmental awareness amongst built environment professionals, have been perceived as effective tools. Cole et al. (2000) define building environmental assessment methods as tools for evaluating building performance with respect to a broad range of environmental considerations, organized into assessment criteria. That is, Building environmental assessment methods have emerged as a means to evaluate building performance across a broad range of environmental considerations. There are many assessment systems in different countries. It is hard to say one system is better than the others because they are all designed based on a national background, which induces the limited utilization of these systems. Therefore, to develop a world wide accepted green building assessment system has captured considerable attention.

\section{Green building assessment system}

The literature review of green building assessment tools shows a fruitful result. In the past several years, many environmental assessment systems for buildings have been built, including the BREEAM in U.K, the LEED in U.S.A, the QUANTUM in Netherlands, the PromisE in Finland, the ECO-PRO in Germany, the EQUER in France, the CASBEE in Japan and the Athena in Canada etc. These assessment methods vary in scope, structure, format and complexity. There is not any assessment tool which can be widely used although the world until the birth of GBTool. It can be traced back to the Green Building Challenge '98 (GBC '98). In order to develop a universal method for measuring building performance across a range of environmental issues, "The Green Building Tool (GBTool)" assessment framework came into being. Collaboratively developed by 19 countries, it can be regarded as an international building environmental assessment method and is applicable to different types of buildings as well. In GBTool assessment system, the building performance is structured hierarchically by criteria and sub-criteria based on 
different performance issues and categories, including resource consumption, loading, indoor environmental quality, service quality, economics, pre-operation management and commuting transport etc. It addresses not only the biophysical environmental issues in the most comprehensible and dynamic manner of all the evaluated methods but also all building performance areas and all stages of the building lifecycle. The customization of benchmarks and weighting system provides opportunities to make GBTool adaptable in different circumstance.

Although GBTool undoubtedly provide a systematic and useful approach for green building assessment industry, many researchers have pointed out that green building assessment system should be adjusted according to the background of a certain country and region. Cooper (1999) contends that such current international attempts at developing a universal, standardized method for assessing the environmental performance of buildings are inherently flawed. He argues that such methods are found wanting in that they are culturally implicit, and that such methods or tools "treat the sustainability [of the] wider built environment as simply a matter of energy and mass flows without due regard to the socio-economic and political dimensions of sustainability" (Cooper, 1999). In this context, Richard Hill et al. (2002) conducted research to answer the question whether building assessment tools originated from developed countries could satisfy the different environmental focus and socio-economic needs of South Africa. Recently, the name of GBTool has been changed to SBTool. All these research has shown that before using a universal green building assessment tool, it is necessary to analyze the local situation and identify the adaptability of using such a tool in a specific country and region.

In 2006, the government of China established the Green Building Assessment Standard. The main content consists of six indicators including land saving and outdoor environment, energy saving and efficiency, water saving and efficiency, material saving and efficiency, indoor environment quality, operation management. The assessment of each indicator is classified into three items, the controlling item, the normal item, and the optimizing item. The controlling item of each indicator must be met as a basic foundation. The normal item shows the general content of green building. The standard can be applied in residential and commercial buildings. The result of green building assessment is classified into 3 grades according to the amount of sub-items the building met.

\section{The application of green building assessment system: advantages and disadvantages}

\subsection{Advantages}

The main advantages for the application of green building assessment system in China are government support and awareness of the general public.

\subsubsection{Government support}

In 1994, the Chinese White Book named 'The 21 Century Agenda -Population, Environment and Development in China' has been put forward, which sets out the general strategy and action plan for sustainable development in China. Actually, as country with long civilized history, sustainable development concept is already identified in the old times. Xun $\mathrm{Zi}$, a philosopher in Chinese history, has systematically put forward the theory that people should have respect for the ecologic rules and attach importance to the sustainable application of natural resources. Therefore, one of the advantages is the government support of using green building assessment tool because sustainable construction has already been taken as a basic policy in the construction industry. To realize sustainable construction, laws and policies have been made under the direction of sustainable strategy in Chinese construction sector. The Environmental Protection Law and the Construction Law can be regarded as the basic foundation of green building in China. On the based of these two laws, many regulations and rules have been made which cover different profiles of green building assessment, such as the Regulations on Environment Protection Management of Construction Project, the Energy Saving Management Regulation for Civilian Building and the Commercial House Performance Assessment institution etc. These regulations and rules have formed a basement to launch a life-cycle green building assessment system in the future.

\subsubsection{Awareness of the general public}

Another advantage is that more and more people gradually attach importance to sustainable construction. Compared with some developed countries, the percentage is not very high at present. However, the concept of green building has been widely accepted by the general public, especially in the urban area, which can be demonstrated by the urban housing market. Houses with better green building performance are usually sold with higher prices. Many people are apt to buy houses which can be good at energy saving and with good indoor environment quality. During the decoration stage of the houses, people no longer pay much attention to the luxury and honourable materials but the healthy ones. What they think about is how to make their home comfortable and healthy rather than to make them in the lap of luxury. Therefore, the awareness of green building by the general public will form the market-driven power for the application of green building assessment. 


\subsection{Disadvantages}

The main difficulties found as to the application of green building assessment system are lack of basic data of implementing assessment, lack of professionals, as well as lack of interest from real estate developers. In addition, the difficulty of build a unified standard in a large country is another problem that should be solved in advance.

\subsubsection{Lack of basic data of using assessment system}

The main difficulties of using green building assessment system are related to the general lack of environmental data and standardization. There still does not exist a completed LCA database to easily access the environmental profiles for materials and products, which is the fundamental requirement for green building assessment. Moreover, it should take a long time to establish an energy performance reference which can be used throughout different climatic regions of China while directly using international databases is not available.

\subsubsection{Lack of professionals}

To implement green building assessment in the construction sector, there must exist a large number of professionals who are good at both construction and environmental knowledge. However, this requirement has not been met for the moment. Although there are many architects and engineers who are experienced in project design and construction, few of them have education or training background of sustainable construction, let alone green building assessment practice, which is an obstacle to push green building assessment forward in China.

\subsubsection{Lack of interest from real estate developers}

Although sustainable construction has been regarded as a good policy, the real estate developers, designers and contractors are only interested in if they can get more profit. Developing a project with high-level green building performance may not directly lead to an immediate payback. Except for some of the performance such as energy saving and indoor environment quality which are concerned by the consumers, the developers seldom really devote themselves to promote the life-cycle environmental loading performance of a building, notwithstanding they always boast they have develop a green building project in the advertisement. Without a definite reward, the developers are not really interested in using green building tool to assess and improve their project performance. Therefore, to push forward the application of green building assessment system, other related policies or institutions should be made such as definite tax reduction or exemption to the developers, designers and general contractors.

\subsubsection{Difficulty of build a unified standard in a large country}

As one of the largest countries in the world, the variance of climate, natural resources and economic situation etc. in different regions has made it difficult to develop a unified green building assessment system for the whole country. For example, water resource is now a really problem for the development in the north part while it is a light issue in the south region. In addition, the non-equilibrium of economic development in different regions has also made it difficult for the implementation of a unified green building assessment system.

\section{Strategies}

Based on advantages and disadvantages analysed above, strategies for the application of green building assessment system in China should be as follows:

\subsection{The government should make policy to promote green building assessment}

To promote the application of Green building assessment system, the government should make compulsory policies and institutions which can directly incorporate life-cycle green building assessment into the basic construction and operation process. Although there already exists a policy for environmental assessment in the feasibility study of a construction project, this assessment is limited in the feasibility phase and only concentrates on the assessment of environment pollution of the project. Therefore, a life-cycle green building assessment system should be employed for the assessment of the life-cycle green building performance of a construction project. Using such a system should be a compulsory requirement. At the same time, as a reward, corresponding tax reduction and exemption policy should be made which can be cooperated with the application of green building assessment system. In addition, in the government ranking system to the design and construction enterprises, achievement in building project with green building performance should be regarded as an assessment indicator.

\subsection{Green building assessment should be in accordance with the international standard}

The globalization of economy results in an oneness of standard. When establishing a green building assessment system in a certain country, it is very important to make it in accordance with the international standard. Therefore, the establishment of building an assessment system should be based on an international standard such as SBTool. That is, the indicators of the assessment system and the approach to use the system should both refer to the international standard. The advantage of referring an international system can not only make the assessment system more reasonable, but also make the result more acceptable. 


\subsection{Green building assessment standard needs to be customized}

As the climate, natural resources and economic situation vary from region to region, customizing should be used according to the local and regional situation in the application of green building assessment system. The customizing process lies in two parts. one is that the indicator system should be adjusted according to the local situation, the other is the weight of each indicator must be defined based on its importance in a certain region. Moreover, since the assessment process of green building assessment system is onerous and usually takes a long time, it is recommended that green building assessment system can be divided into a two stages assessment system. The first stage is to assess the important inherent characteristics of a building such as resource consumption, loading, indoor environmental quality, service quality and economics etc. The second stage is to assess the performance of pre-operation management and commuting transport. The customer can choose the two assessment stages step by step.

\subsection{Fundamental database needs to established in advance}

Before the application of green building assessment system, the fundamental database for green building performance should be established. Although there exist some international databases, it cannot be directly employed in the Chinese context. The database must be built according to the situation in China. It should be a completed LCA database which includes the detail energy consumption and environment loading data of construction materials and products. This onerous work should be done as soon as possible because it will take a long time.

\subsection{A large number of professionals of green building assessment needs to be developed}

To push ahead with the application of green building assessment system, there must be enough professionals who are good at the knowledge of sustainable construction. Unfortunately there still lack of such professionals to carry out green building assessment work at present. The only way to get rid of this obstacle is by launching training and education program. This work should also be started immediately, as it is a major premise for the application of green building assessment system. Meantime, the assessment system to the professionals and organizations that will carry out green building assessment work should be gradually set up. The manage system for these assessment professionals and organizations should be mature, otherwise the green building assessment work cannot be implemented in perspective and the assessment result is meaningless.

\section{Conclusion}

Sustainable construction is the application of sustainable development in the construction industry. To realize sustainable construction, establishing green building assessment system is undoubtedly a right way. However, when choosing a green building assessment tool, we usually be puzzled by whether to use an international assessment tool or totally make a tool for our own. From the authors' point of view, the effective way is to choose an international tool as a basement and then make a custom-build tool according to Chinese situation. A good assessment tool should be judged according to its potential application. In other words, it must be designed according to the local and regional situation from the guideline system to the labeling tools as well as implementation strategies. And it must coordinate with the local laws, rules and standards. In this paper, the author has put forward a set of strategies for implementing green building assessment. Further research needs to be conducted based on this initial journey to promote green building in China.

\section{Acknowledgement}

The author would like to thank the National Natural Science Foundation of China (Project No. 70302015) and the Shanghai Leading Academic Discipline Project (Project No.B310) for the support of this research.

\section{References}

CIB(1999). Agenda 21 on Sustainable Construction, CIB Report Publication 237, Rotterdam.

Cole, R.J., G. Lidnsey and J.A. Todd.(2000). Assessing life cycles: Shifting from green to sustainable design. Proceedings: International Conference Sustainable Building 2000, Maastricht, Netherlands, pp. 22-24.

Cooper, I..(1999).'Which focus for building assessment methods - environmental performance or sustainability? Building Research \& Information, 27(4/5), pp. 321-331.

Richard Hill et al. (2002). Sustainable building assessment methods in South Africa: an agenda for research, Paper presented at the International Conference on Sustainable Building 2002, Oslo, Norway. 